\title{
Collaboration in Design Education
}

Compiled and edited by Marty Maxwell Lane and Rebecca Tegtmeyer (2020); book cover designed by Alberto Rigau; published by Bloomsbury, London, UK; 176 pages. ISBN: 978-1-3500-5903-0

REVIEW BY MEAGHAN A. DEE ${ }^{1}$ AND JESSICA JACOBS ${ }^{2}$

1. Associate Professor of Graphic Design, College of Architecture and Urban Studies, School of Visual Arts, Virginia Tech, Blacksburg, VA, USA

2. Associate Professor of Design Management, Business and Entrepreneurship Department, Columbia College Chicago, Chicago, IL, USA

Suggested citation: Dee, M. \& Jacobs, J. “Collaboration in Design Education.” Review of Collaboration in Design Education, compiled and edited by Marty Maxwell Lane and Rebecca Tegtmeyer. Dialectic, 3.1 (2021): pgs. 145-151.

Published by the AIGA Design Educators Community (DEC) and Michigan Publishing.

DOI: http://doi.org/10.3998/dialectic.14932326.0003.107

STABLE URL: http://hdl.handle.net/2027/spo.14932326.0003.107 

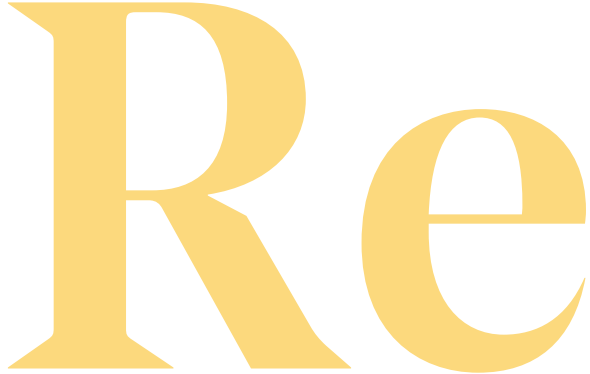

\section{Collaboration in Design Education}

Compiled and edited by Marty Maxwell Lane and

Rebecca Tegtmeyer (2020); book cover designed by

Alberto Rigau; published by Bloomsbury, London, UK; 176 pages. ISBN: 978-1-3500-5903-0

REVIEW BY MEAGHAN A. DEE ${ }^{1}$ AND JESSICA JACOBS ${ }^{2}$

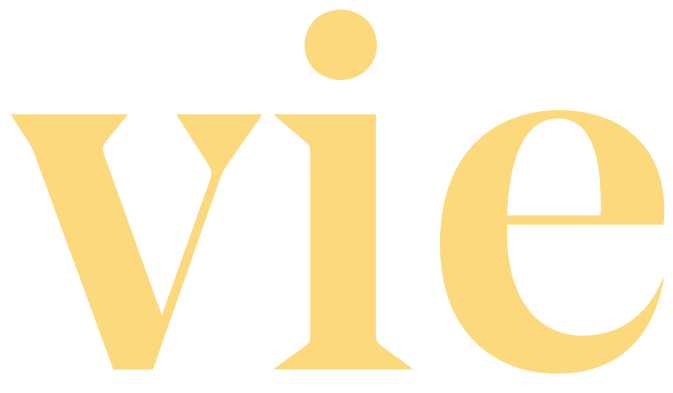

methods. She argues that successful design is a co-creation process in which designers "design[s] with people rather than for people". " At its core, design is presented as being a collaborative endeavor, and, as such, the authors offer that a thorough design education will provide a wide variety of opportunities for collaboration.

The book is divided into six chapters: Community Collaborations with Students, Faculty Sharing Knowledge to Broaden Student Experience, Peerto-Peer Learning Across Disciplines, Confronting Bias in Cultural Exchanges, Intra-disciplinary Faculty Collaboration, and Industry Interviews. Each section features between two and four case studies, and these include critical reflections on their effectiveness written by their respective instructors. These highlight what worked well, what their facilitators would do differently if they could operate them again, and the specific challenges each of the collaborative groups faced. As Tyler Galloway, an associate professor of graphic design at the Kansas City Art Institute, states in a reflection on a collaborative project he helped orchestrate called ThinkTank 2020, the process of designing collaboratively, "truly is both difficult and rewarding." Descriptions of addressing the real challenges inherent in collaborations between designers and various types of stakeholders includes concrete descriptions of and about how the various authors confront a wide range of struggles, and these are wellarticulated throughout this text. Some common issues addressed in this array of case studies include coordinating schedules (particularly when working across time zones), delegating tasks, and deciding how "hands-on" design faculty
In the foreword, contributor Meredith Davis contextualizes the contents of this book squarely within the framework and history of participatory design 
should remain as a given project's schedule evolves.

Additionally, across the breadth of case studies they present, the authors offer various approaches that explain how collaboration between designers, design educators and community stakeholders who have little to no design experience is possible, even when conditions are less-than-perfect.

The opening chapter Community Collaboration with students profiles institutions and programs that build on a commitment to civic engagement and co-creation with their community partners by co-designing with them to address specific community-based needs. The authors featured in this section reference several other helpful sources, including the text Developing Citizen Designers by Elizabeth Resnick, ${ }^{2}$ that promote a more proactive approach for helping students position themselves as community advocates as they learn to engage in human-centered, community-rooted design methods. At the same time, the authors acknowledge the principal challenges inherent in community collaboration, such as identifying and maintaining stable community partnerships. They also suggest some potential solutions, such as working with people who service similarly focused systems at their universities and looking to consulting resources in the local or regional design industry for support or information.

Each chapter has a series of design educator-authored case studies which are diverse in their approaches. In the first chapter, the "Farm-to-Market" case study is particularly notable for its detailed description of how faculty members Meta Newhouse and Caroline Graham Austin at Montana State
University developed and sustained a collaboration between local farmers and university students to create new, value-added products that met some specific needs on behalf of the farmers. The instructors guided students from the inception of initial ideas through to the development of conceptually advanced prototypes by maintaining a focus on empathy-building, usertesting, and iterating in response to ongoing feedback they received from the farmers as their design processes progressed. Newhouse and Austin provide a detailed timeline, learning objectives, pedagogical methods, and an assessment rubric and critique methods that other design faculty can learn from and adapt into their own courses.

In all of the case studies, the design educators who authored them also provide reflections on what worked and what didn't during the evolution of each of the projects they describe. These candid insights illustrate the common challenges so many design educators face in developing these kinds of projects, while helping them work together to build collective learning and knowledge. While we found these large-scale projects and insights to be helpful, we also delighted in some of the small (and easy) takeaways from this array of case studies. For instance, Newhouse and Austin shared the team ice-breaker they used: "A week prior to the start of the term, we sent an email to all participants instructing them to bring a food item to the first class that represented something about themselves, and told them that they would have to introduce themselves, and their food, to the rest of us." ${ }^{3}$ Because working collaboratively is about facilitating effective communication, building and sustaining relationships, and forming and maintaining trust, we found
1 Maxwell Lane, M. \& Tegtmeyer, R. Collaboration in Design Education. London, UK: Bloomsbury, 2020 , p. 8.

2 Resnick, E. (editor). Developing Citizen Designers. London, UK: Bloomsbury, 2017.

3 Maxwell Lane, M. \& Tegtmeyer, R. Collaboration in Design Education. London, UK: Bloomsbury, 2020, pp. 45. 
4 lbid., pp. 100.

5 These comments also appear in Davis' book "Teaching Design: A Guide to Curriculum and Pedagogy for College Design Faculty and Teachers Who Use Design in Their Classrooms." Davis, M. Teaching Design: A Guide to Curriculum and Pedagogy for College Design Faculty and Teachers Who Use Design in Their Classrooms. Allworth Press, New York, NY, USA: pgs. 42-44. that these tips and tricks to be quite helpful for design educators looking for ideas that could help get course projects off to a strong start.

The second and third chapters focus on how the sharing of knowledge between both design faculty and their university- or college-based peers helps to foster learning across disciplines. This robust collection of case studies feature descriptions of collaborations between design educators and practitioners and people hailing from a range of fields and disciplines outside of design including sculpture, printmaking, and photography, creative writing and jazz, psychology, and education. The descriptions offered in these chapters about how peer-to-peer learning is scaffolded are especially helpful.

The fourth chapter, Confronting Bias in Cultural Exchanges, lays the groundwork for international collaborations informed by design processes, and also provides methodologies for challenging preconceived sociocultural stereotypes. Maxwell Lane and Tegtmeyer state herein that, "both faculty and students inherently have a cultural bias that needs to be discovered and openly discussed in order for cross-cultural collaborations to be successful. By looking to other disciplines for understanding of why these biases exist in the first place and how meaning is constructed in cultures outside of our own, [design] faculty can coach students in broadening their worldview and practicing empathy." The contents of this chapter promote the idea that if design students can better understand their position in the world and genuinely open up their thinking in ways that encompass cross-cultural collaboration, they will become both better designers and also better citizens.

The authors who have contributed work to this chapter have also produced work that promotes the following theme: "If we truly value the individual needs and contexts of our students and our communities, we cannot separate design education from current events." Between mid-2019 and mid-2021, we have experienced a global pandemic, increased anti-Asian violence, a "Black Lives Matter" movement that continues to gain momentum as a means to overcome racial bias, and an attempted coup of the United States government. These authors all present work that support the idea that design is a part of the zeitgeist, (i.e., the "spirit of the times"), and, as such, suggest that we cannot ignore the context that shapes it, and that it also helps to shape. Additionally, as Meredith Davis stated during the "Curriculum and Pedagogy for Complex Problems" roundtable that transpired at the 2020 (virtually-held) AIGA Design Conference, "ethics, inclusion, and community should be at the core of all that we do." ${ }^{5}$ The authors of the case studies in this chapter remind us that one way that we can ensure that this actually happens is to positively engage with the communities that we affect and are, in turn, affected by. Additionally, these authors argue that design educators need to be proactive in confronting their own biases, and, as they do this, provide a platform that allows their students to do the same.

In this chapter, a case study that stands out is titled "Sustainability and Interactive Experience," which describes how two design professors from the United States and Qatar developed a cross-cultural partnership that 
involved significant contributions from their American and Qaterian students. Denielle Emans and Kelly Murdoch-Kitt have since published the valuable text Intercultural Collaboration by Design: Drawing from Differences, Distances, and Disciplines Through Visual Thinking (Routledge, 2020), which details their efforts to utilize design processes to help forge and sustain cross-cultural understandings. We appreciated the specificity of techniques they employed in their writing of this chapter that described how they asked their students to engage each other in ways that allowed them to explore their intercultural differences and their respective potentials to be affected by socially and culturally rooted biases.

The fifth chapter, Intradisciplinary Faculty Collaboration, provides a welcome set of case studies that examine something that is often overlooked in the documentation of design pedagogycollaborations among graphic design educators. As a set, these case studies provide examples of workshop-based curricular interventions that seek to challenge power hierarchies by facilitating shared experiences between students at different levels of experience. This is achieved by immersing them in learning experiences that ask them to determine the factors that affect the creative trajectories that guide the development of their own work, and by using rapid iteration as a means to develop a pleasurable and insightful collaborative design experience.

The case study titled "SWEAT Workshop" (a report and analysis about the Summer Workshop for Experimentation and Thought that transpired during recent summers at Bowling Green State University) describes a set of design-based learning experiences facilitated by Bowling Green State University instructors Jenn Stucker and Amy Fidler. The SWEAT Workshop is guided by a philosophical statement that declares a design student should "unapologetically meet life where it is." ${ }^{6}$ This approach indicates a commitment to attempting to understanding the individual needs of both the students and faculty members who are involved. For example, Fidler and Stucker recount that when they began this intensive, they were both raising young children and were unable to pay for childcare during the summer months, and this spurred them to identify ways to integrate their children's presence into the day-to-day activities of the workshop. Rather than letting this situation be seen as a negative, they reframed the situation, focusing on positive possibilities. While collaboration in Design Education was written before the onset of COVID-19, this mindset of adaptability could benefit many in the pandemic and post-pandemic world. Educators have dealt with personal hardships and caretaking for many years, but the pandemic forced many of these responsibilities out of the shadows and into a space that allowed them to be more closely examined and addressed. The "big suggestion" offered here is that perhaps all of our teaching and learning institutions could be better served by allowing for the embracement of individual faculty members as whole people.

The final chapter of the book features a set of industry interviews that bring in much-needed perspectives regarding if and how the teaching strategies articulated throughout this book actually connect to real-world design practices. Additionally, it was
6 Maxwell Lane, M. \& Tegtmeyer, R. Collaboration in Design Education. London, UK: Bloomsbury, 2020, p. 134. 
enlightening to read about what the design practitioners featured in this chapter gained from their partnerships with design educators. For example, Matthew Muñoz, Chief Design Officer of New Kind, valued the students' different perspectives and the shift in energy that students bring to projects by virtue of their being on campusand learning from the experiences they are immersed in there-rather than in the office.

Finally, some of the most enlightening and compelling portions of this book appeared in the portions of the case studies devoted to student reflections. Reflecting on her engagement with a specific project experience, one student offered that, "I believed that it's a designer's job to control every little aspect of the process, but I learned later on that design is a collaborative process, and with collaborative or participatory design, you can't control everything... but you can lead the process as a designer." Readers of Collaboration in Design Education who are design educators may find comments like these useful as they strive to "make the case" to build similar experiences within their own curricula.

While the authors do provide well-chosen case studies throughout this text that can be used as a springboard to help design educators spark their own ideas for guiding classroom experiences, we feel that design educators who read this text would benefit from being exposed to a broader discussion about how to facilitate the teaching of different types of collaboration. It has been our experience that many design educators are so caught up in the day-to-day demands of teaching design well-writing projects, critiquing, grading, answering emails, meeting with students-that they tend not to have the time (or energy) to critically consider the broader pedagogical contexts that affect and are affected by the work they are doing. These contexts now include the planning and hands-on facilitation of collaborative projects that challenge emerging designers to work with people who have little to no formal design training or education. This well-crafted book would become even more useful if it could present its readers with more clearly articulated methodologies for planning and engaging in crossdisciplinary collaboration, perhaps even a "tips and tricks" summary, or a "discoveries" page that occurs at the end of each section. Collaboration in Design Education left us wanting to hear more from the author regarding their critical thoughts and analyses about what has been presented in each of these case studies. Despite this criticism, this collection of case studies remains an excellent contribution to the current paucity of existing resources available that address the facilitation of cross-disciplinary collaboration in design education.

The over-arching theme that unites each of the case studies on offer in this text is that planning and facilitating collaborative endeavors between those immersed in design education and those outside of it is hard work but well-worth the effort. Cross-disciplinary, collaborative projects help design students learn the skills necessary to work with othersespecially those whose backgrounds differ from their own-and provide them with broadly informed opportunities for self-reflection, confidencebuilding, and empowerment. While readers of Collaboration in Design
Education can benefit from the case study discoveries presented within it, they will undoubtedly encounter their own specific struggles as they attempt to provide their students with opportunities like the ones recounted here. Fortunately for them, this book provides many useful insights about how design educators (and their students) can pivot during, and adapt and learn from collaborative experiences. In aggregate, the diverse range of case studies presented here provide realistic operational frameworks for projects that design faculty can effectively implement, while also articulating the underlying ideas in ways that are transferable to other disciplines and audiences. 
The typographic structure of Dialectic employs typefaces from four different families: Fira (Sans and Mono), Freight, Idealista, and Noe Display.

Fira Sans was introduced in 2013 as Feura Sans, and was designed by Erik Spiekermann, Ralph du Carrois, Anja Meiners and Botio Niktoltchev of Carrois Type Design. Fira Sans and Fira Mono (the latter was designed as a monospaced variant of the former) are based on Speikermann's typeface designs for the FF Meta family of typefaces, which originated in the 1980 s. Fira is classified as a humanist, sans-serif typeface family.

The Freight family of typefaces - "Big," "Display," "Sans," and "Text was designed by Joshua Darden in the early 2000 s and is comprised of over 100 styles. The Freight families are currently licensed through Darden Studio, and, with the exception of the "Sans" variants, may be classified as a display, serif typefaces.

The Idealista family was designed by Tomáš Brousil and released in 2010. It is comprised of ten style variations and five weights. It may be classified as a geometric, sans serif typeface, and is available from MyFonts.com.

The Noe Display family was designed by Lauri Toikka in 2013 and is available through the Schick Toikka digital foundry. It is comprised of four Roman and four italic variants, ranging in weight from "regular" to "black." It may be classified as a display serif typeface, and shares some formal characteristics (sharp, angled serifs, high contrast between thick and thin strokes) with the Noe Text family. 